\title{
LA PREGUNTA POR LA CREATIVIDAD. NOTAS SOBRE EL ANÁLISIS DE LA PRODUCCIÓN RECIENTE EN LAS INDUSTRIAS CREATIVAS ARGENTINAS
}

\author{
THE QUESTION OF CREATIVITY. \\ NOTES ON THE ANALYSIS OF THE RECENT PRODUCTION IN THE \\ CREATIVE INDUSTRIES \\ IN ARGENTINA
}

Paula Miguel*

\section{Resumen}

Este trabajo reflexiona sobre la producción en las industrias creativas, tomando el caso argentino de la ciudad de Buenos Aires. En primer lugar, da cuenta del contexto general donde se inscriben estos procesos. Luego presenta una elaboración en relación con el lugar de la creatividad en este enfoque y los debates en torno a las industrias culturales y creativas, brindando algunos datos que dan cuenta de la relevancia de este sector productivo, al igual que de las políticas públicas desarrolladas en la ciudad de Buenos Aires. Por último, se ocupa de presentar algunos casos para comprender las transformaciones que en los últimos años pudieron registrarse en la producción cultural y simbólica, en relación con la creatividad y la emergencia de nuevos productores.

\section{Palabras clave}

Creatividad, producción simbólica, industrias creativas, Argentina.

\footnotetext{
* Doctora en Ciencias Sociales. Es profesora e investigadora en la Universidad de Buenos Aires. Su trabajo de investigación se centra en el análisis de las industrias creativas y sus transformaciones recientes, con un enfoque especial en la producción simbólica y las dimensiones culturales de la economía. Correo electrónico: paula@sociales.uba.ar
} 


\begin{abstract}
The aim of this work is to think about production in creative industries, focusing in the case of Buenos Aires, Argentina. First, it presentes a general accounting of the context in which these processes are inscribed. The article then presents an elaboration on the place of creativity in this approach and discussions on cultural and creative industries, providing some data to support the relevance of this sector and its related public policies. Finally, some cases are presented to understand the transformations recorded in recent years of symbolic and cultural production in relation to creativity and the emergence of new producers.
\end{abstract}

\title{
Keywords
}

Creativity, symbolic production, creative industries, Argentina.

\section{Introducción}

Este trabajo propone algunos puntos que emergen del análisis de la creatividad en el marco de las industrias creativas (UNCTAD, 2008, 2010), centrándose en los resultados de la investigación enfocada particularmente en la ciudad de Buenos Aires, en el período 2001-2010. Teniendo en cuenta las transformaciones que se dieron en los últimos diez años en algunas zonas de la producción de las llamadas "industrias creativas" (UNESCO, 2006; OIC, 2008; UNCTAD, 2008, 2010), es interesante destacar la relación entre economía y cultura que se expresa en ellas, así como las nuevas formas emergentes de producción e intermediación simbólica. Tomando como punto de partida el caso argentino, pensando en la década del noventa y lo que esta significó en términos de transformaciones económicas, sociales, políticas y culturales ${ }^{1}$, sumadas estas a la experiencia de una profunda crisis durante 2001-2002, se plantea la pregunta a propósito de la relación entre ese pasado inmediato y su impacto en las formas de producción cultural y simbólica

1 Durante los años noventa se registraron oficialmente más de 16.000 quiebras de empresas, un $50 \%$ más que en la década previa (MECON, 2001). a medida que se transitaba por los primeros años del nuevo milenio y surgían nuevos productores y formas de producción (Miguel, 2009, 2010; Rubinich y Miguel, 2011).

En ese contexto, se analizaron distintos espacios de producción, tratando de identificar los reposicionamientos más significativos y los espacios de mayor dinamismo en la producción de la industria editorial, la industria discográfica, la producción cinematográfica, el diseño de indumentaria y la publicidad; esta última vinculada con un sector del análisis de mercado. Así, nos enfocamos en aquellos espacios que los propios actores - productores e intermediarios-definen, de alguna manera, como más o menos "independientes" y que desde la perspectiva de análisis cuentan con la propiedad de realizar sus propios emprendimientos productivos.

Como situación general se observa que en el contexto de crisis mencionado emergieron formas novedosas de producir en distintos espacios, muchas veces desembocando en trayectorias exitosas. Uno de los aspectos de estas transformaciones tiene que ver con el desarrollo de trayectorias empresariales incipientes; apuestas al desarrollo de emprendimientos que pueden identificarse en algunos casos con la conformación de un 
“espíritu emprendedor” (Miguel, 2010). Al mismo tiempo, se registraron cambios en ciertas zonas de producción empresarial más tradicional que comienzan a realizar un mayor nivel de inversión, vinculadas a la producción simbólica.

A partir de allí, a manera de hipótesis de inicio, es preciso señalar que las transformaciones ocurridas en el interior del campo cultural en la ciudad de Buenos Aires, en el transcurso de las últimas décadas, obedecen a cambios propios de la lógica interna del mismo, en combinación con las coyunturas económicas por las que atravesó el país, al igual que con los procesos culturales y económicos globales. En otras palabras, es necesario dar cuenta de las dinámicas de producción cultural y simbólica que, en relación con las transformaciones en el contexto nacional y global, dan lugar a la actual configuración del mismo.

En este sentido debe entenderse que la introducción de las transformaciones mencionadas tuvo un fuerte impacto sobre las configuraciones no solo de la producción cultural, sino también de la organización de los canales y circuitos de difusión, circulación y consumo. Si bien estos elementos se pueden enmarcar a veces en procesos globales, la forma concreta que adquieren responde a modos singulares y locales de manifestación, expresión y apropiación de esos procesos más amplios, es decir, entendiéndolos como resultado de la convergencia entre dinámicas globales y nacionales complejas, que pueden comprenderse como procesos de "glocalización" (Robertson, 1995).

Por otra parte, yendo a las prácticas específicas, la profesionalización -o en algunos casos, la conformación de un tipo de expertise específica- en algunas zonas de producción del campo cultural constituye una clave para comprender la aparición de nuevos sujetos, formas institucionales y de gestión, donde las estrategias adoptadas en la producción creativa se encuentran tensionadas entre lo cultural y lo económico. Al mismo tiempo, se tuvo en cuenta el vínculo entre las políticas culturales, fundamentalmente las del gobierno de la ciudad de Buenos Aires y los distintos casos trabajados, pensando esos procesos de mayor especificación de las competencias y su relación con la producción en el interior de cada espacio. Esto nos permitió identificar los impactos del proceso de profesionalización sobre la producción y el nivel organizacional, específicamente relacionado con la toma de decisiones estratégicas, dando cuenta de las tensiones que resultan del hecho de que las industrias culturales se encuentran en una zona liminal entre lo estético/cultural y lo empresarial/comercial.

De esta manera, se trata de caracterizar la creatividad no como un concepto en abstracto, sino en una estrecha relación con el estado actual de la producción en el área de las industrias creativas. A la vez, esto permite también avanzar sobre conclusiones más generales respecto al modo en que se producen cambios en el campo de la cultura y su contexto social. En este sentido, se parte del supuesto de que el cambio sufrido por los distintos segmentos del campo de la cultura-aun cuando estos se encuentren enraizados en redes de relaciones que exceden los límites de dicho campo-se explican, en gran medida, por características propias de su configuración interna, al mismo tiempo que es necesario tener en cuenta las estrategias y trayectorias de los productores en un espacio social más amplio. Se busca demostrar que lejos de lo que las miradas post-facto sugieren, durante el período de análisis los cambios no siguen un patrón único, sino que en cada caso se dan movimientos, relaciones complejas y a veces contradictorias. Así, la explicación de los cambios ocurridos en la producción creativa no puede reducirse al influjo de la 
racionalidad económica predominante ni de las tendencias globales.

En ese sentido, se presentarán a continuación tres apartados que permitirán pensar, en primer lugar, en el contexto general donde se inscriben los procesos creativos. Luego se presenta una elaboración en relación con el lugar de la creatividad en este enfoque y los debates en torno a las industrias culturales y creativas, brindando algunos datos que dan cuenta de la relevancia de este sector productivo y de las políticas públicas desarrolladas en la ciudad de Buenos Aires. Por último, se presenta el aporte de algunos sectores para comprender las transformaciones que en los últimos años pudieron registrarse: la producción cultural y simbólica, en relación con la creatividad y sus productores.

\section{Un contexto amplio: globalización económica y cultural}

El desarrollo de las nuevas formas de producción cultural a las que hacemos referencia coincide con un período de transformaciones estructurales que se dan no solo en la sociedad local de la ciudad de Buenos Aires, sino también a nivel global. Por eso es necesario referirse a ese contexto general y dar cuenta de sus implicancias sobre los procesos particulares y las especificidades que interesa analizar aquí. Cada uno de los casos productivos analizados pueden pensarse en relación con elementos que tienen que ver con procesos de globalización económica y cultural. En lo que atañe a los aspectos económicos, ubicamos el contexto de una nueva fase de expansión de la economía capitalista, pero cuyo desarrollo conlleva cambios importantísimos y complejos en todos los aspectos de la vida social (política, cultura, trabajo, formación de identidades, etc.) y, por lo tanto, también en las relaciones sociales.
En este orden de ideas, la apertura de los sistemas económicos implica la disminución de políticas estatales proteccionistas y reguladoras, un aumento del volumen del comercio internacional, la expansión de los mercados financieros y la interpenetración de las industrias a través de las fronteras nacionales. El flujo incesante de personas, capitales y bienes culturales, como rasgo característico, supone un nivel de intercambios inéditos en la historia del mundo. Esto se integra en una sociedad de flujos basada en la circulación constante de información, que se constituye bajo el paradigma organizativo de la red, resultando la interconexión un rasgo distintivo de la sociedad global (Castells, 2006; Lash, 2005). En el universo de los productos culturales, estos intercambios se dan con enorme intensidad, en tanto constituyen un entramado de expresiones culturales interdependientes sostenidas por la comunicación global (Lash y Lury, 2007).

En relación con estos procesos, también se registra una tendencia a la flexibilización y el deterioro de las condiciones de trabajo, así como una tendencia al aumento de las tasas de desempleo y una caída del nivel de empleo en general. Al mismo tiempo, se registra un deterioro de las relaciones laborales, segmentación de la fuerza de trabajo y una tendencia al descenso de las remuneraciones, debido a que las empresas deben reducir costos y maximizar la productividad. En los casos particulares que aquí se plantean, la apertura del país a las importaciones de diversos orígenes será clave para comprender el deterioro de algunos sectores de la industria local.

También existe una relación entre estos procesos y la apuesta hacia carreras empresariales individuales en este nuevo contexto; los trabajadores se trasladan mayormente al sector de producción de servicios, y los diferentes procesos que acompañan este fenómeno acentúan la individualización de 
quienes buscan insertarse en el mercado de trabajo, haciendo que la idea de devenir "su propio jefe" o un "emprendedor" resulte más plausible y tenga mayores perspectivas de éxito que en contextos históricos anteriores. Las trayectorias de los productores creativos que aquí analizamos son en parte emergentes de estas dinámicas, como aspecto de un escenario global que, a su vez, está fragmentado respecto de sus actores sociales.

Estos últimos se autodefinen e identifican cada vez más con estilos de vida que comprenden un conjunto de vivencias y experiencias, y ya no tanto con una pertenencia a determinada clase social, en un sentido clásico. Claro que por estar fuertemente vinculados al consumo, estos estilos de vida no son de libre elección, sino que responden a posibilidades económicas e ingresos determinados. Además, al cruzar transversalmente los distintos sectores sociales, contribuyen a erosionar la idea de clase social. En este contexto, se define, entonces, un tejido de relaciones sociales en el que participan actores locales y transnacionales que moldean la complejidad de la producción económica y cultural.

Siguiendo con el planteo anterior, durante los últimos años se registra un efecto de relativa homogeneidad en las grandes ciudades y en sus habitantes, especialmente entre aquellos sectores medios y altos que pueden acceder a ciertos niveles de consumo. En este sentido, en cualquier ciudad global (Scott, 1999; Sassen, 2007) se pueden encontrar las mismas marcas, centros comerciales similares, pero no solo eso. También en términos de oferta gastronómica, por ejemplo, encontramos cadenas de comidas rápidas, aunque igualmente, en menor escala, aparece una oferta de especialidades mexicanas, japonesas y árabes. Los mangas japoneses circulan tanto como la música africana, la práctica del yoga, el street wear londinense, el cine iraní, los vinos argentinos o chilenos y otros elemen- tos "exóticos", que pueden entenderse como consumos de distinción para quienes definen su estilo de vida en relación con estas selecciones y recortes de diferentes backgrounds culturales.

Este proceso puede entenderse como el advenimiento, si bien incipiente, de un extenso y multifacético sistema global de aglomeraciones de productos culturales en torno a los cuales se definen identidades, más o menos volátiles, ligadas a estilos de vida. A pesar de los efectos negativos que tiene la cultura comercial de masas sobre muchas de las formas tradicionales de producción, la globalización no parece apuntar a una uniformidad cultural, sino, más bien, a aumentar la variedad de opciones que se ofrecen a los consumidores individuales (Power y Scott, 2004:13).

La globalización cultural se refiere a la transmisión a través de las fronteras nacionales de formas variadas de arte y medios (Kawashima, Crane y Kawasaki, 2002). Continuando con este planteo, esta circulación ocurre generalmente entre países avanzados o en desarrollo, especialmente aquellos que constituyen mercados para los medios o que poseen suficientes niveles de ganancias para invertir en cultura, arte e instituciones artísticas y culturales. Pero esto no implica la presencia de una cultura global homogénea, sino que se trata de un fenómeno complejo y diverso, donde se constituyen culturas globales que tienen sus orígenes en elementos variados que provienen de diferentes naciones y regiones.

Se trata de un proceso en el cual una serie de flujos culturales producen ambas cosas: en primer lugar, al relacionar paquetes de cultura que comparten elementos que previamente estaban aislados, produce el doble efecto de una homogeneidad cultural y un desorden cultural; en segundo lugar, da lugar a culturas transnacionales, que pueden entenderse como genuinas "terceras culturas" orientadas más 
allá de las fronteras nacionales (Featherstone, 1990). Esto último resulta interesante para pensar los circuitos internacionales de ciertos productos simbólico-culturales que, a su vez, son económicos y se anclan en lugares específicos dentro del mapa urbano. De alguna manera, los productores "hablan un mismo idioma" e interpelan a un público que comparte esos códigos.

En relación con estos procesos, se puede observar una multiplicidad de productos culturales que se ponen en circulación desde fines de los años ochenta a nivel global y que impactan en la región y, particularmente, en la ciudad de Buenos Aires. Esta ciudad, a partir de la década del noventa especialmente, registrará importantes transformaciones que la ubicarán como una ciudad global. Entre esos procesos que afectaron también otras ciudades latinoamericanas se inicia la implementación de servicios de TV por cable, abriendo la llegada directa a contenidos de cadenas de televisión como, por ejemplo, HBO. La industria de la música se expande, particularmente la de habla inglesa, que se distribuye mediante las grandes compañías discográficas. Las transformaciones globales también introducen los avances tecnológicos realizados en materia de comunicaciones y de circulación online con el desarrollo de Internet, que habilitan y hacen posible la circulación de productos culturales más segmentados, under o contraculturales a medida que se abarata también, en términos relativos, el acceso a los medios de producción.

Así, en la ciudad de Buenos Aires se da un proceso de actualización respecto a las tendencias globales económicas y culturales, a la vez que se segmentan cada vez más marcadamente los espectros de consumos, apuntando a hipotéticos estilos de vida diferenciados. Al mismo tiempo, también se hacen más accesibles medios y dispositivos de producción, debido a los avances tecnoló- gicos y comunicacionales, que requieren una inversión de capital relativamente pequeña, pero que tienen el potencial de desembocar en empresas exitosas en algunos casos en los que se logra explotar el componente simbólico como motor de la producción de valor económico.

\section{La producción entre la cultura y la economía, y la pregunta por la creatividad}

El análisis de lo cultural en una economía determinada tiene que ver con la consideración de las diferentes construcciones simbólicas que se dan en torno a la producción económica. Por un lado, se suele decir que la primacía de lo económico atraviesa todos los órdenes de acción y, en ese sentido, se extiende también al ámbito de la cultura. Pero, al mismo tiempo, el arte y la cultura se están convirtiendo en una dimensión que ocupa una parte cada vez mayor de la producción de bienes y servicios. La producción económica lleva cada vez más estampado el sello de lo simbólico en la construcción de su valor. A través de la combinación entre las amplias esferas de la cultura y la economía, se generan productos innovadores y conceptos de proyectos que, en los diferentes casos, desarrollan a la vez su propia demanda. Eso, como se señaló, excede la mera producción económica y material del objeto; a través de dinámicas colectivas se ponen en juego una variedad de elementos simbólicos que contribuyen a la puesta en valor de los productos.

A los efectos de problematizar la producción que se da en este solapamiento entre cultura y economía es necesario tener presente el funcionamiento en paralelo de los distintos procesos sociales que confluyen en el proceso de producción y puesta en valor de los productos. Se entiende que hay una relación conjunta entre los aspectos económicos, sociales y culturales. De esta manera, arte y 
cultura pueden pensarse como resultantes del cambio social y, al mismo tiempo, entenderse como una fuerza motriz del crecimiento económico en un contexto capitalista de producción, dado que la producción de formas simbólicas ha acelerado la diferenciación de los consumidores y de los bienes y servicios de consumo.

En este sentido, la oferta y la demanda están cada vez más impregnadas de contenidos simbólicos, cognitivos y expresivos, ya sea en tanto insumo de la producción o como componente clave de su circulación. La absorción de la producción cultural en la economía se convierte, entonces, en una clave para el debate sobre la relación entre la cultura y la economía (Scott, 2001; Lash y Lury, 2007), y en relación con ello surge en tensión el concepto de "creatividad".

Tal como señala Raymond Williams en su selección de Palabras clave para el análisis de la cultura, el término "creativo" "tiene un sentido general de originalidad e innovación $\mathrm{y}$ un sentido asociado especial de productividad" (2003: 83). Durante el siglo XIX se asocia fuertemente ese término con los de "arte" y "pensamiento", mientras que el término "creatividad", como sustantivo para aludir a la facultad, aparece durante el siglo $\mathrm{XX}$. Este término plantea una clara dificultad: apunta a destacar o hacer hincapié en la originalidad y en la innovación; sin embargo, esta palabra adoptó un uso convencional para describir algunos tipos generales de actividad (tal como "creativo publicitario").

No obstante, este término resulta útil para pensar en el aspecto que resaltaba en otros tiempos: la capacidad de hacer, de crear y de innovar humanas, oscilando entre dos polos en tensión: uno relacionado con algunos de los sentidos de "imaginación", como ensoñación o fantasía, en relación con las prácticas específicas que se denominan artes imagina- tivas o creativas; o con otro vinculado con las ideas de extensión, innovación y previsión, que tienen implicaciones y efectos prácticos y que pueden ser tangibles en algunas actividades y trabajos creativos (Williams, 2003: 84-85). Estas dificultades y tensiones tienen que ver con la complejidad que encarna el análisis de la actividad humana que se representa actualmente con el término "creativo".

Así, se puede entender, en líneas generales, que la creatividad está relacionada con la habilidad de generar algo nuevo; es la producción -ya sea por una o varias personasde ideas o invenciones que son personales, originales y significativas. Ese hacer algo nuevo puede ser en el sentido de "algo que surge de la nada" o en el sentido de darle un nuevo carácter a algo. La creatividad se refiere a un proceso; cuando algo es escrito, por ejemplo, más allá de que luego sea publicado o no, se desarrolla un proceso creativo. Todas las personas son creativas a su manera, pero algunas de ellas van más allá y hacen de eso el centro de su actividad laboral o al menos tratan de que lo sea no solo en términos de personalidad, sino también comercialmente. No se trata necesariamente de una actividad económica, pero puede serlo cuando se produce una idea con implicaciones económicas o productos comerciables. Esta transición entre lo abstracto y lo concreto, entre la idea y el producto, es difícil de definir (Howkins, 2001)

Es allí donde se da una serie de interrelaciones y procesos mayormente simbólicos, en los que intervienen diferentes agentes que contribuyen a la puesta en valor de ese producto, particularmente cuando se trata de productos o servicios vinculados a lo cultural y simbólico. En ese sentido, para entender mejor los procesos de creatividad e innovación en relación con la economía y la producción cultural, es necesario tener en cuenta sus anclajes geográficos (Scott, 1999, 
2006; Mundelius, 2008). Scott (1999) define la economía en relación con la producción creativa como economía cultural, planteada como un espacio en donde tienen lugar densas y complejas relaciones y transacciones entre firmas y productores, que a su vez implican interdependencias formales e informales entre ellas. Estas relaciones muchas veces son inestables, finamente articuladas y frecuentemente mediadas por contactos cara-a-cara.

Esto significa que el mantenimiento de dichas relaciones de manera productiva y provechosa a lo largo del tiempo absorbe mucho tiempo y mucha energía. Por otra parte, dadas estas condiciones de producción, los trabajadores, productores e intermediarios necesitan reunirse diariamente en sitios de trabajo en donde las relaciones personales puedan desarrollarse más dinámicamente. Estas relaciones de contactos personales en donde prima el contacto cara a cara van constantemente recalibrando y ajustando el mercado de trabajo. Las firmas y los productores ocupan locales mutuamente accesibles y el mercado de trabajo funciona como un conjunto de recursos casi-compartidos. Esto resulta válido incluso en aquellas zonas más informales de los emprendimientos, por ejemplo cuando un editor recluta escritores, o un productor musical, artistas para sus sellos; donde, si bien no se registra una relación propiamente contractual o de dependencia, las relaciones adoptan estas formas de redes de contactos.

Las transacciones entre las firmas y los procesos de circulación y reclutamiento en el mercado de trabajo local dan lugar a un proceso de aglomeración que se potencia a sí mismo: la creación de una "atmósfera" particular que usualmente acompaña estos procesos hace que estos núcleos productivos sean cada vez más valorados por los diferentes productores, para quienes se vuelve casi indispensable estar presentes en el espacio para formar parte de esos procesos. Por otra parte, la aglomeración y sus efectos no solo aumentan la eficiencia del sistema productivo, sino también su creatividad. Esto se da, principalmente, en el caso de productos culturales complejos, ya que la mayor densidad de intercambios y relaciones influye en el dinamismo puesto en la producción (Scott, 1999: 811).

Así, la creatividad y la innovación en la economía cultural contemporánea pueden entenderse como fenómenos sociales arraigados en el sistema de producción y en su entorno geográfico, lo cual supone: a) la formación de comunidades culturales; b) la organización de la economía cultural y su propensión a la aglomeración; y c) la lógica temporal de los complejos de producción cultural (Scott, 1999: 814). Siguiendo este planteo, es posible desarrollar la noción de campo creativo desde una perspectiva geográfica (Scott, 2006: 52-55).

Esto resulta útil para describir el campo no solo como un espacio abstracto de relaciones sociales, sino también en tanto espacio concreto en donde estas tienen lugar. En este sentido, se deben precisar algunas cuestiones que tienen que ver con la relación entre el espacio físico, que actúa como soporte de las propiedades sociales de los agentes, y las instituciones que, mediante su distribución, hacen de ese espacio un espacio social o, por decirlo de otra manera, socialmente jerarquizado, donde es posible captar la estructura del sistema de las posiciones constitutivas del espacio de un campo y la estructura del espacio social (Bourdieu, 2003: 168).

Por otra parte, estos planteos entre la producción cultural y económica, con categorías y conceptualizaciones que muchas veces, como se ha señalado, se superponen y no logran captar una especificidad unívoca, evidencian un interés por abarcar estos fenómenos de producción, tanto desde las áreas de políticas públicas como desde el análisis sociocultural. 
Sin embargo, estas categorías ofrecen ciertas limitaciones al referir una pluralidad de elementos donde no es posible imaginar un conjunto homogéneo de productos y donde la producción reviste en cada caso características específicas con roles y formas de circulación y distribución diferentes.

Mientras que la noción de habitus que propone Bourdieu (1991) permite colocar la mirada analítica en el lugar donde convergen la subjetividad individual y la estructura social, particularmente es interesante retomar el enfoque que Bourdieu (1995, 2000, 2003) propone acerca de la lógica presente en la producción cultural, donde rige una idea de rechazo de lo comercial, una lógica de denegación de lo económico. De esta manera, el capital útil es el capital simbólico, que confiere la facultad de consagrar o valorizar objetos o personas mediante procedimientos no del todo explícitos que podrían asociarse a algo "mágico". Asimismo, funciona una ideología carismática que sostiene la figura del genio, del autor iluminado, del creador.

Hay aquí una serie de relaciones públicas que se dan en torno a la convicción sobre el valor del producto, por parte de la prensa especializada, por ejemplo, y otros intermediarios. Esto se encuentra en relación con la producción de la creencia: sin la creencia en que el producto "vale" simbólicamente no sería posible hablar del mismo o percibirlo como tal. Por eso es importante comprender no solo cómo se crean determinadas obras o productos, sino también cómo se produce la creencia que las acompaña. En este sentido, el principio del "poder" creador -o creativo- no es explicable por las partes individualmente, sino que solo puede encontrarse en el conjunto del propio campo; el conjunto de las prácticas que se dan entre productores, consumidores y quienes median entre ellos (Bourdieu, 1995, 2003).
Siguiendo este enfoque, que pone el acento en esa serie de relaciones colectivas, será importante tener en cuenta las nociones de intermediario cultural y de artesano artístico que Bourdieu (2000: 358-369) identifica con los miembros de lo que denomina "la nueva pequeña burguesía", quienes se abocan a carreras nuevas y mantienen una familiaridad con la cultura y unas redes de contactos sociales importantes que les permiten manifestar alta competencia en términos de capital cultural y social entre las clases medias, a la vez que son propensos a inclinarse por las expresiones que se encuentran en los márgenes de la llamada "cultura legítima".

Más allá de las posiciones de clase a las que hace referencia Bourdieu, analizando la sociedad francesa de los años setenta y que pueden no necesariamente ajustarse a nuestra coyuntura actual u otros contextos, la fuerza de estas nociones se encuentra en que ponen el énfasis en un tipo de trabajadores (aunque adopten la forma de pequeños empresarios) que aparecen en medio de los productores y los consumidores. En este punto, es necesario prestar atención a la adhesión habitual, irreflexiva y acrítica a las rutinas de producción establecidas, a las fórmulas de trabajo y de reproducción rutinaria de contenidos y fórmulas. Esto permitirá desentramar o desagregar las prácticas de los intermediarios culturales para resolver cuándo, cómo y bajo qué condiciones su actividad estética puede ser creativa o innovadora (Negus, 2002).

Estos elementos conceptuales, en relación con la producción simbólica y creativa, brindan algunos ejes para el abordaje que permitan identificar elementos en común entre áreas productivas diferentes, a la vez que pudiera hacer también un aporte para la comprensión de procesos más generales. Así, decidimos usar de manera flexible algunos conceptos y categorías que nos permitieran generar hipótesis de trabajo, y pensar en 
relaciones entre las distintas áreas de producción cultural y creativa, así como establecer tipos de dinámicas, relaciones y modos de organización y producción en el interior de cada una de ellas.

\section{Las industrias creativas y las políticas públicas en la ciudad de Buenos Aires}

A mediados de los años noventa, las industrias culturales se convirtieron en un tema de investigación en el espacio académico internacional. Es importante tener presente lo que significa la producción cultural en nuestros días y el desarrollo de productos y servicios vinculados a ella ${ }^{2}$. Ciertamente, se trata de uno de los sectores productivos que registraron una fuerte expansión en el conjunto de la economía mundial, con un crecimiento de casi un $9 \%$ anual entre 2000 y 2005 (UNCTAD, 2008: 106).

En el caso de la ciudad de Buenos Aires, también empezaron a desarrollarse trabajos de investigación e incluso surgieron instituciones dedicadas al estudio de las industrias culturales, como el Observatorio de Industrias Culturales (OIC), que a partir de 2006 pasó a llamarse Observatorio de Industrias Creativas. La razón de este interés por las industrias culturales y creativas es múltiple: las industrias culturales se han perfilado como un sector en crecimiento, se han desarrollado como industrias exportadoras y representan uno de los principales empleadores en los países de altos ingresos.

2 En términos cuantitativos, en 1980 el comercio global de bienes culturales estaba valuado en 95 mil millones de dólares, alcanzando unos 380 mil millones en 1998. Si en esta categorización se tienen en cuenta también los bienes y servicios creativos, entonces se registra un aumento significativo del volumen de intercambios, que implica una variación de 227,4 mil millones de dólares para 1996 a 424,4 mil millones en 2005 (UNCTAD, 2008:106).
Entendemos, a partir de la categorización de la Conferencia de las Naciones Unidas sobre Comercio y Desarrollo (UNCTAD), que las industrias creativas abarcan los ciclos de creación, producción y distribución de bienes y servicios que tienen creatividad y capital intelectual como materia prima; constituyen un conjunto de actividades basadas en el conocimiento, enfocadas pero no limitadas a las artes, generando potencialmente ganancias de los derechos de propiedad intelectual. Comprenden productos tangibles y servicios intelectuales o artísticos con contenido creativo, valor económico y objetivos de mercado; se encuentran en el cruce entre el sector artesanal, el de servicios y el industrial y constituyen un nuevo sector dinámico en el comercio mundial (UNCTAD, 2010: 8).

En el caso de la ciudad de Buenos Aires (OIC 2010: 10-12), las actividades que pueden enmarcarse en el concepto de industrias creativas participaron entre 2003 y 2008 del $8,2 \%$, en promedio, del valor agregado de la ciudad. En términos de su impacto económico, las industrias creativas superaron en participación a ramas como "construcción" $(6,32 \%)$ o "servicios de hotelería y restaurantes" $(4,99 \%)$, entre otras. Además, son particularmente dinámicas: el conjunto de las industrias creativas ha crecido un $68 \%$ en términos reales (a precios constantes) entre 2003 y 2008, con un ritmo superior que la economía porteña en su conjunto, que para algunas actividades en particular marca un crecimiento con tasas que duplican y hasta triplican su valor agregado. También ha crecido el empleo en el sector de las industrias creativas, si se toma como referencia el periodo 1999-2009, llegando a registrar un aumento promedio de un $14 \%$ anual para el conjunto de las actividades, lo que significó la creación de más de 60 mil nuevos empleos durante esos años y dando como resultado que las industrias creativas representen casi el $10 \%$ del empleo en la ciudad en 2009. 
Por otra parte, aumentó paralelamente la importancia de los bienes y servicios creativos en el comercio exterior argentino. Las exportaciones crecen de manera notable a tal punto que, entre 2002 y 2009, quintuplican su monto total, pasando de 437 millones de dólares a más de 2.300 millones.

En materia de políticas públicas, en la ciudad se ha seguido una línea de fomento a las actividades culturales y se registró un incremento significativo del presupuesto que el GCBA asigna al área de cultura, pasando de 146 millones de pesos en 2001 a 651 millones de pesos en 2009 (OIC, 2010: 195-197) y se prevé para 2011 un presupuesto de casi 865 millones de pesos, donde se les asigna a las áreas y políticas en relación con las industrias creativas un $3,4 \%$ del presupuesto total (GCBA, Presupuesto 2011).

Esto tuvo que ver con la implementación de políticas públicas específicas en los distintos niveles de gobierno, que alrededor del año 2000 comenzaron diferentes iniciativas relacionadas con las industrias creativas. Más tarde, la gestión de Aníbal Ibarra continuó trabajando en este sentido. Se desarrollaron políticas que intentaban fortalecer y fomentar el diseño en general (indumentario, industrial, de software, gráfico, etcétera) en el plano local, ya fuera promoviendo vinculaciones entre empresarios y diseñadores o simplemente facilitando las condiciones para que los diseñadores pudieran convertirse en empresarios. En este sentido, las apuestas más fuertes tuvieron que ver con la creación en el año 2000 del Centro Metropolitano de Diseño (CMD), cuyas líneas de microcréditos desarrolladas conjuntamente con el Centro de Apoyo a la Microempresa (CAM) abrían la posibilidad de acceder a créditos a tasa $0 \%$, que fueron aprovechados por algunos de los productores culturales, junto con los proyectos IncuBA. Con el cambio de gestión en 2007, la Subsecretaría de Industrias Culturales pasa a ser la
Dirección General de Industrias Creativas y, planteando una continuidad, aparecen nuevas líneas de promoción ${ }^{3}$.

A partir del momento en que comienzan a gestionarse operativamente estas políticas públicas y a manifestarse en nuevos espacios institucionales como el CMD, se produce un paulatino recambio: gran parte de la gestión cultural es llevada a cabo por nuevos equipos de jóvenes con formación más actualizada y especializada que la del personal de planta. Mediante esta actualización de los cuadros administrativos de estas áreas se incorporaron graduados de profesiones afines para que colaboraran en el desarrollo de las distintas actividades y políticas públicas. Estos jóvenes profesionales contratados contribuyeron a oxigenar la perspectiva con la que la ciudad trataba muchos temas en relación con la cultura en general (estos casos fueron comunes en la gestión del canal de TV Ciudad Abierta $\mathrm{y}$ en los distintos festivales que organizan -tango, teatro, BAFICI- así como otros programas especiales). Muchas veces entre estas contrataciones de personal especializado y los productores destinatarios de la acción de las distintas áreas o políticas públicas se daba un encuentro entre pares, personas que podían haber compartido los espacios de formación, pero también compartían un lenguaje común en sentido generacional.

Así, sobre todo las primeras acciones que tendían a desarrollar las industrias creativas en la ciudad se dieron en el marco de reuniones

3 Son ejemplos el programa de "Asesoramiento en negocios para industrias creativas" y otras formas de financiamiento como los programas "Apoyo a la Competitividad PYME", "Buenos Aires emprende", "Desarrollo emprendedor" de la Subsecreataría de Desarrollo Económico; programas de la Dirección de Comercio Exterior; y algunos productos específicos del Banco Ciudad como el Paquete de productos para emprendedores - empresas unipersonales, y sociedades de hecho y Ciudad Competitiva. 
conjuntas entre distintos sectores interesados, muchas veces sobre la base de contactos personales. Sobre todo en los comienzos, este tipo de iniciativas se dieron en un marco de cierta informalidad, donde hubo marchas y contramarchas, hasta desembocar en políticas públicas concretas, como la decisión de crear el Centro Metropolitano de Diseño. Muchos otros proyectos que surgieron de esos encuentros terminaron por diluirse con el tiempo. Sin embargo, en un sentido amplio, más allá de la efectividad y logros de los programas puntuales y la adecuación que puedan tener respecto de las necesidades de los destinatarios, los esfuerzos de las políticas de difusión del GCBA a través de las distintas gestiones han cosechado algunos frutos: es la primera "Ciudad del Diseño" de la UNESCO desde agosto de 2005 y fue nominada "Capital Mundial del Libro 2011”. Al mismo tiempo, la ciudad también se ha posicionado como un importante centro turístico, funcionando las distintas áreas de las industrias creativas como un atributo especial de la ciudad. Este tipo de reconocimiento contribuyó al fortalecimiento, la estabilidad y la continuidad de las políticas públicas que se mantienen actualmente, y a la difusión de la producción desarrollada por los llamados "emprendedores creativos” (Beltrán y Miguel, 2011).

\section{Diferentes áreas creativas. Emprendedores creativos ${ }^{4}$}

Pensar en la producción creativa, en un entramado colectivo, supone pensar en dos tipos de objetos que deben ser diferenciados: a) productos, es decir, los productos culturales que surgen de cada una de estas zonas; y b)

$4 \quad$ Agradezco especialmente a Hernán Vanoli y Ezequiel Saferstein; Diego Vecino; Martín Azar y Martina Masera Lew; Matías Galimberti; Walter González y Pedro Orden; y Gastón J. Beltrán por la colaboración en el desarrollo de la investigación (para mayor detalle véase Rubinich y Miguel, 2011). instituciones y sus espacios en los cuales se producen, intercambian y circulan dichos productos. En ese sentido, se exploraron algunas áreas de producción creativa en la ciudad de Buenos Aires, enfocándose en los sectores más dinámicos que emergieron luego de la crisis de 2001 y que plantearon en común la existencia de una particular forma de productor: el emprendedor creativo, que siendo parte de un sector de consumidores expertos, en relación con la circulación global de productos culturales y simbólicos sofisticados, comienza a producir para el mercado local bienes de distinción simbólica.

Más allá de las lógicas propias de cada espacio de producción, y con los matices propios de cada manifestación en una trayectoria vital que es única e individual, existen elementos que convergen en lo que puede llamarse un "espíritu emprendedor" asociado a un clima ideológico-discursivo que en los años noventa enfatizaba los valores de la independencia, la capacidad emprendedora y la eficiencia (Sennet, 2006: 83-130). Esto reúne las bases de un espíritu compartido por los productores, que se presenta como el soporte para poder trascender el contexto adverso de crisis y dedicarse de plano a una apuesta propia, como empresario o emprendedor vinculado a la producción creativa o simbólica. Estos emprendedores se presentan como empresarios vinculados con industrias no tradicionales, ligadas a la cultura y al desarrollo de productos creativos, caracterizadas por la creación de un valor agregado esencialmente simbólico.

La explicación de su éxito no se vincula ni con un aprovechamiento eficiente de las economías de escala ni con la explotación de ventajas comparativas o alianzas estratégicas con empresas líderes. Lo que las caracteriza es un vuelco hacia la creatividad como forma de generar valor y la puesta en práctica de un tipo particular de innovación vinculada con la resignificación y revalorización de 
productos ya existentes (Beltrán y Miguel, 2011). La creatividad como estrategia es lo que permite comprender la capacidad adaptativa de este conjunto de nuevos empresarios que, con escaso capital inicial, en muchos casos, sin embargo corrían con la ventaja de estar desprovistos de lastres organizacionales, como gran cantidad de personal a cargo, y contaban con herramientas conceptuales para el desarrollo de pequeñas empresas de producción creativa.

Observar las trayectorias de algunos de los sujetos que se cuentan entre los empresarios "exitosos" del mundo de las industrias creativas nos ayudará a comprender mejor uno de los aspectos clave que todos ellos comparten: la existencia de un "espíritu emprendedor". Los sujetos cuyas trayectorias reconstruimos comparten otra importante característica: pueden ser catalogados como "exitosos". El éxito significó la presencia y continuidad en el tiempo de los emprendimientos, el reconocimiento de los pares y de instancias de consagración y legitimación (como premios, subsidios y concursos), así como la visibilidad ante un público más amplio mediante la presencia en la prensa especializada.

La sólida formación profesional de muchos de estos sujetos como clave para su éxito da cuenta de la existencia de un proceso de creciente "profesionalización de la creatividad"; su intervención en industrias culturales donde se valora la creatividad y la imaginación es habilitada -y en parte legitimada- por las credenciales educativas, aunque en última instancia el reconocimiento tenga que ver con ciertos efectos vinculados a la lógica carismática del "talento". En este sentido, el desarrollo profesional no se limita a la obtención de títulos universitarios, sino que es entendido como un proceso constante que se realiza en distintas instancias y ámbitos de formación.
En general, se trata de productores provenientes de sectores medios urbanos, que valoran las credenciales educativas (Adamovsky, 2009). En ese sentido, la carrera universitaria no solo es un espacio de formación, sino también un lugar donde se generan contactos y relaciones, al igual que se adquiere la destreza para abordar desafíos y obstáculos que exceden lo estrictamente curricular. En el caso del diseño de indumentaria, por ejemplo, el hecho de haber pasado por una misma institución educativa (en la gran mayoría de los casos, por la carrera de Diseño de Indumentaria y Textil de la Universidad de Buenos Aires) contribuyó a inspirarles un sentimiento de pertenencia. Los primeros egresados se consideraban parte de un grupo de personas pujantes -primero estudiantes, luego diseñadores/ empresarios- en una constante búsqueda de la auto-superación (Miguel, 2010).

La mayoría de los diseñadores han desarrollado su propia empresa, muchas veces como respuesta a la imposibilidad de insertarse en el mercado de trabajo. Como provenían en su gran mayoría de estratos medios, sus primeros pasos comerciales se caracterizaron por un bajo nivel de inversión y por la preponderancia del esfuerzo personal. Los esfuerzos por lograr un espacio y superarse profesionalmente se realizan "a pulmón". Estas primeras iniciativas, sin embargo, no parecen responder a un plan empresarial premeditado. Retrospectivamente, hacerse empresario es visto como la única manera de poder trabajar en lo que se había estudiado. La propia empresa no era un fin en sí mismo sino un medio para ejercer la profesión. Esto ocurre también en el caso de la producción en cine, donde la formación profesional y sus distintas instituciones resultan particularmente clave. El rol de las escuelas de cine como nuevos actores institucionales de este espacio resulta clave para entender este espacio de producción, ya que incluso la institución educativa por la que se ha transitado 
marca la inserción posterior en el mercado, registrándose en algunos casos la presencia de directores que se relacionan muy dinámicamente con las productoras, creando luego, en algunos casos, las propias (Rubinich y Miguel, 2011).

Con matices, esto se encuentra presente en otras áreas de industrias creativas, aunque existen diferencias según el nivel de desarrollo de cada una en términos económicos y simbólicos. Así, podemos distinguir entre emprendimientos que se dan en un contexto de desarrollo incipiente, como en el caso de los pequeños pero dinámicos sellos discográficos. Allí, quienes los desarrollan poseen recorridos educativos variados y suelen tener otra inserción laboral como fuente principal de ingresos. Entre los nuevos productores emergentes en la industria discográfica y en la producción musical es posible observar la emergencia de una cultura de producción específica que se distancia de los mecanismos de producción de las grandes empresas transnacionales del sector y se relaciona ideológicamente con el valor de la "independencia", que trasciende un estilo musical específico y que es posible rastrear en distintos géneros musicales, donde emergen junto a los artistas, nuevos productores que desarrollan sellos discográficos pequeños y medianos, y animan una red de circulación para los mismos, ganando notoriedad y legitimación a medida que logran sostener sus emprendimientos en el tiempo.

Algo similar ocurre en los casos de las pequeñas editoriales, donde las micro-editoriales representan un $65 \%$ del mercado editorial. Los editores generalmente se formaron en carreras relacionadas con las letras y sus ingresos provienen de tareas como la docencia, el dictado de talleres literarios y el periodismo escrito, que les permite, al menos en un momento inicial, sostener su apuesta empresarial. Esto permite ubicar la produc- ción de nuevas editoriales "independientes" -herederas de una tradición que piensa la edición casi como gesto militante, y vinculadas a un tipo de producción artesanal-, en una brecha que muchas veces la construcción de los indicadores por parte de otros actores de la industria no llega a abarcar completamente. Estos indicadores a la vez influyen en el tipo de políticas de subsidios y fomento que se aplican en el sector, y que muchas veces dejan al margen o no apuntan un mayor desarrollo del potencial de esos pequeños editores "independientes". Editores que no solo editan, sino que funcionan también como una red de ámbitos de sociabilidad literaria, donde se puede encontrar cierta heterogeneidad entre las diversas tendencias en el interior de las "microeditoriales" que no son nuevas, pero que empezaron a proliferar con vitalidad desde finales de la década del noventa y cobraron importancia durante los últimos diez años en cuanto a la significativa cantidad de títulos editados.

En el lado opuesto se encuentran las áreas de investigación de mercado y publicidad, que se han desarrollado como nichos particulares dentro de un universo organizacional mucho más complejo, intentando dar cuenta de la producción cultural y simbólica en una escala mayor, donde existe una dimensión más comercial, con un peso y tradición empresarial más importante que en las modalidades emergentes señaladas anteriormente, pero donde encarna un fuerte contenido simbólico en términos de producción de creatividad. En ese sentido, en el campo publicitario se registra un crecimiento muy marcado, especialmente luego de la crisis económica de 2002, logrando en el último tiempo una alta productividad, así como el posicionamiento y reconocimiento a nivel internacional, pero donde al mismo tiempo aparecen tensiones relacionadas con la incorporación de nuevas tecnologías, por un lado, y la competencia 
y posicionamientos de distintos agentes del medio publicitario, por otro.

Esas influencias tentativamente tienden a aislar poco a poco al sector de productores creativos, centrados en la producción de un cierto contenido "mágico" como la creatividad, que comienza a ser tensionada y discutida por los diferentes agentes. Allí la definición de las reglas de producción de creatividad entra en disputa desde diferentes intereses y formas de sociabilidad empresarial, desde el lugar de producción de saber específico estandarizado que corresponde, entre otros actores, a las centrales de medios.

Así, los elementos constitutivos de prácticas sociales que se pueden encontrar en común se dan con diferente intensidad y presentan variaciones en cada uno de los miembros, haciendo que el grupo no resulte homogéneo. Cada productor genera su propia marca, empresa y proyecto estético y conceptual, con sus propias particularidades. Sus apuestas aparecen fuertemente relacionadas con la expresión personal, el hacer lo que a uno le gusta, para aquello que se preparó.

\section{Comentarios finales}

Si la visión de oportunidad y la disposición a arriesgar aproxima a estos emprendedores a los de un estilo más clásico (Schumpeter, 2005), el tipo de recursos que movilizan los convierten en emprendedores de un tipo particular. En efecto, lo que caracterizó a estos empresarios de las industrias creativas fue la escasa inversión económica en el punto de partida, siendo los principales recursos puestos en juego de tipo simbólico. La capacidad de trabajo, la "creatividad" y cierta noción del "talento", antes que el dinero, fueron los recursos sobre los que se construyeron las trayectorias de éxito.
Es en este sentido que la creatividad posee un vínculo estrecho con el mundo del arte y de la producción cultural. El ser creativo, la imaginación, la inventiva son atributos que suelen ser pensados como positivos dentro de estos universos de producción. Sin embargo, en los procesos que analizamos aquí, la creatividad, entendida como capacidad espontánea para crear, entra en tensión con la profesionalización. Esto ocurre en tanto al tiempo que existe una alta valoración de los títulos, las trayectorias exitosas se presentan como el resultado del "talento personal", donde el misterio de la creación en un cineasta, en un diseñador o en un creativo publicitario, o de la sensibilidad para reunir artistas en una editorial o sello discográfico, excede la reproducción mecánica de una destreza o habilidad específica profesional.

Los aprendizajes y experiencias de los años previos en momentos de adversidad económica, sin embargo, se constituyeron en un know how que en muchos casos adquirió un altísimo valor de mercado, sumado a su formación profesional: los emprendedores creativos argentinos resultaron expertos en el manejo de situaciones de incertidumbre extrema. Al mismo tiempo, las industrias creativas, dado que gran parte de su producción insume no tanto materias primas sino intangibles, se perfilan como los espacios ideales para desarrollar en contextos volátiles o de imprevisibilidad, ya que las apuestas requieren relativamente escasa inversión de capital económico.

De esta manera, los elementos desarrollados hasta aquí y las tensiones que se presentan contribuyen a comprender la creatividad, entendida como la capacidad de crear valor simbólico que a veces consigue reconvertirse exitosamente en reconocimiento económico, generando la ilusión de generarse virtualmente de la nada o con recursos relativamente escasos en términos económicos. Sin embargo, 
la raíz de su producción es muy nutrida en términos simbólicos e intangibles, donde los procesos de puesta en valor pueden ser más o menos opacos -en relación con la lógica individualista del talento, del creador, de la inspiración-, pero que en todos los casos insumen una gran energía de trabajo colectivo y preparación individual, en términos de conocimientos adquiridos, para su puesta en valor y circulación, que es lo que se intentó desentramar en este recorrido.

\section{Referencias}

Adamovsky, E. (2009). Historia de la clase media argentina: apogeo y decadencia de una ilusión 1919-2003. Buenos Aires: Planeta.

Beltrán, G. (2009, 11-14 de julio). Empresarios culturales: toma de decisión y estrategias de innovación en el campo de las industrias culturales. En XXVIII International Congress of the Latin American Studies Association. Rio de Janeiro.

Beltrán, G.J. y Miguel, P. (2011). La creatividad al poder. Acumulación simbólica y reacomodamientos exitosos en contextos adversos. XXVIII Congresso da ALAS. Recife (Brasil).

Bourdieu, P. (1991) El sentido práctico. Madrid: Taurus.

Bourdieu, P. (1995). Las reglas del arte: génesis y estructura del campo literario. Barcelona: Anagrama.

Bourdieu, P. (2000). La distinción: criterios y bases sociales del gusto. Madrid: Taurus.

Bourdieu, P. (2003). Creencia artística y bienes simbólicos: elementos para una sociología de la cultura. Argentina: Aurelia Rivera.
Castells, M. (2006). La sociedad red. Barcelona: Alianza Editorial.

Caves, R. (2000). Creative industries: contracts between art and commerce. Cambridge: Harvard University Press.

Featherstone, M. (1990). Global Culture: Nationalism, Globalization and Modernity. Londres: Sage Publications Ltd.

Featherstone, M. y Lash, S. (1995). Global modernities. London: SAGE Publications.

Hartley, J. (2005). Creative Industries. Malden MA: Blackwell Pub.

Howkins, J. (2001). The Creative Economy: How People Make Money from Ideas. Londres: Allen Lane.

Kawashima, C. y Kawasaki (2002). Global Culture: Media, Arts, Policy and Globalization. Kioto: Routledge Inc.

Lash, S. (2005). Crítica de la información. Buenos Aires: Amorrotu.

Miguel, P. (2009). Los recorridos del diseño de indumentaria en la ciudad de Buenos Aires. Apuntes de Investigación del CECYP, 15, 47-69.

Miguel, P. (2010). Creatividad y éxito en un contexto adverso. La paradójica conformación del campo de producción de diseño de indumentaria en la ciudad de Buenos Aires (2000-2005). (Tesis Doctoral). Buenos Aires: Universidad de Buenos Aires, Facultad de Ciencias Sociales.

Ministerio de Economía y Finanzas Públicas (MECON) (2001). Informe Económico Anual 2001. Buenos Aires: MECON. 
Mundelius, M. (2008). The Reliance of Berlin's Creative Industries on Milieus. Berlin: VDM Verlag.

Negus, K.R. (2002). The Work of Cultural Intermediaries and the Enduring Distance between Production and Consumption. Cultural Studies, 16(4), 501-515.

Observatorio de Industrias Creativas (OIC) (2008). Informe: la economía creativa de la ciudad de Buenos Aires. Delimitación y primeras estimaciones. Período 20032007. Buenos Aires: Dirección General de Industrias Creativas.

Observatorio de Industrias Creativas (OIC) (2010). Anuario de las Industrias Creativas. Buenos Aires: Dirección General de Industrias Creativas.

Power, D. y Scott, A.J. (2004). Cultural industries and the production of culture. Londres: Routledge.

Robertson, R. (1995). Glocalization: TimeSpace and Homogeneity-Heterogeneity. En Featherstone y Lash. Global modernities. London: SAGE Publications.

Rubinich, L. y Miguel, P. (2011). Creatividad, economía y cultura en la ciudad de Buenos Aires 2001-2011. Buenos Aires: Aurelia Rivera Libros.
Sassen, S. (2007). Una sociología de la globalización. Buenos Aires: Katz.

Schumpeter, J.A. (2005). Business cycles: a theoretical, historical, and statistical analysis of the capitalist process. Eastford CT: Martino Publishing.

Scott, A.J. (1999). The cultural economy: geography and the creative field. Media Culture Society, 21, 807-817.

Scott, A.J. (2001). Global city-regions: trends, theory, policy. Nueva York: Oxford University Press.

Scott, A.J. (2006). Geography and economy. Oxford: Clarendon Press.

UNESCO (2006). Comprender las Industrias Creativas. Las estadísticas como apoyo a las politicas públicas. Nueva York: United Nations.

United Nations Conference on Trade and Development (UNCTAD) (2008). Creative economy report 2008. Nueva York: United Nations.

United Nations Conference on Trade and Development (UNCTAD) (2010). Creative economy report 2010. Nueva York: United Nations.

Williams, R. (2003). Palabras clave: un vocabulario de la cultura y la sociedad. Buenos Aires: Nueva visión. 